Our Nature (2004) 2:33-34

\title{
A New Report of Prawn, Macrobrachium altiforns (Henderson) From Singhia River Biratnagar, Nepal
}

\author{
Anu Sharma and B.R.Subba \\ Tribhuvan University \\ Department of Zoology \\ Post Graduate Campus, Biratnagar, Nepal
}

\begin{abstract}
The prawn Macrobrachium altiforns of family Palaemonidae recorded from Singhia river Biratnagar, Nepal is described.
\end{abstract}

Keywords: Prawn, Macrobrachium altiforns, Morphometry

\section{Introduction}

Prawns are found in rivers, streams, cannels, ponds etc. of both hills and terai. The work on prawn in Nepal is in infant stage. There exists scanty of information pertaining to taxonomy and diversity of prawn of Nepal. Several researchers have made contribution to the taxonomy and distribution of freshwater, estuarine prawns and marine shrimps from neighboring countries (Henderon and Matihari 1910, Tiwari 1947, Holthulus and Roas 1965, Yaldwyn 1966). From Nepal, eight species of genus Macrobrachium have been reported from Kaligandaki and Narayani river (Shrestha et al. 2001). Taking the above fact into consideration an effort has been made to study prawns of Biratnagar.From the collection only one species of the genus Macrobrachium could be identified and confirmed from available literature. The work of identification and confirmation for other species is under process.

\section{Materials and Methods}

Prawns belonging to family Palaemonidae were collected from Singhia river Biratnagar with the help of local fishermen and brought to laboratory of Zoology Department of Post
Graduate Campus, Biratnagar. They were preserved in 5\% formalin for further study.

\section{Description M. altiforns (Henderson)}

Collection site- Singhia river Biratnagar, 6male, 8-female, total length, male 70-75mm, female $55-63 \mathrm{~mm}$.

\section{Diagnostic features}

RF-110-12/3; ant. scale pointed. Apex horizontal to very slightly upturned; convexity starts nearly from $1 / 3^{\text {rd }}$ of length of its origin; 3-4 teeth on carapace; teeth are not erect; $1^{\text {st }}$ paraepod: finger $=1 / 2$ carpus; ischium, merus, palm and finger hairy; $2^{\text {nd }}$ paraepod: unequal or equal, palm $>=$ finger, palm broader than finger; 2-3 blunt teeth with 6 tubercle on immobile finger but in mobile fingers 3-4 unequal teeth at irregular intervals cutting edge of mobile finger with 4 tubercles. Maximum size collected $75.0 \mathrm{~mm}$.

\section{Results and Discussion}

The present specimen agrees with the species described by Henderson in the morphometry but in few respects it shows some minor differences as in $M$.altiforns (Henderson) the apex of the rostrum 
Anu Sharma and B.R. Subba / Our Nature (2004) 2:33-34

recorded is inclined downward or horizontal , two teeth on carapace. But in the present specimen the apex is horizontal to slightly upturned and 3-4 teeth on carapace. The average maximum size recorded by Dutta 2001, in his specimen M. altiforns is $47 \mathrm{~mm}$ but the average maximum size of species described at present is $75.0 \mathrm{~mm}$. As Shrestha et al. (2001) only a list has been given, no comparison could be made with the present species. The differences recorded in the same two species may be due to different geographical, environmental factors, physical and chemical parameters of water body.

\section{Acknowledgements}

Authors are grateul to Post Graduate Campus, (T.U.) Biratnagar for providing laboratory facilities and fishermen who helped in catching prawns from the river.

\section{References}

Dutta ,N.K. 2001. Studies on systematic and distribution of prawns in Assam J.Bomb. Nat. His. Soc. 91(1): 18-25.

Henderson, J.R and G. Matthari 1910. On certain species of palaemon from south India. Rec.India Mus 5:227--306.

Holthuis, L.B. and J.R. Roas 1965. List of shrimps and prawns of economic value.FAO. Fish.Tech. Pep. 52:21.

Kunju ,M..M. 1965. Preliminary studies on the biology of the palaemonid prawns Leander stylierns $\mathrm{H}$. Milne Edwards .Crustaceans 6(3): 404-441.

Shrestha, J. A.S., Tamrakar and D. Edds 2001. Shrimps of Kaligandaki and Narayani Rivers. Biodiversity Vol.1. No. 2:3.

Tiwari, K.K.1947. Preliminary description of two new species of palaemon from Bengal. Rec .India Mus. 45(4):329-331.

Yaldwin, J .C. 1996. New records of prawn of chilka lake with notes on their distribution. Science and Culture 32 (7):379-380. 